OPEN ACCESS

Edited by:

Dmitry Lim,

Università degli Studi del Piemonte

Orientale, Italy

Reviewed by:

Eric Boué-Grabot,

Université de Bordeaux, France

Paula Canas,

University of Coimbra, Portugal

${ }^{*}$ Correspondence:

David Blum

david.blum@inserm.fr

orcid.org/0000-0001-5691-431X

${ }^{+}$Co-first authors

${ }^{\ddagger}$ Co-last authors

Specialty section:

This article was submitted to

Neurodegeneration,

a section of the journal

Frontiers in Neuroscience

Received: 16 April 2018

Accepted: 11 July 2018

Published: 03 August 2018

Citation:

Cellai L, Carvalho K, Faivre E,

Deleau A, Vieau D, Buée L, Blum D,

Mériaux C and Gomez-Murcia V

(2018) The Adenosinergic Signaling:

A Complex but Promising Therapeutic

Target for Alzheimer's Disease.

Front. Neurosci. 12:520.

doi: 10.3389/fnins.2018.00520

\section{The Adenosinergic Signaling: A Complex but Promising Therapeutic Target for Alzheimer's Disease}

\author{
Lucrezia Cellait, Kevin Carvalho', Emilie Faivre, Aude Deleau, Didier Vieau, Luc Buée, \\ David Blum*, Céline Mériaux ${ }^{\ddagger}$ and Victoria Gomez-Murcia ${ }^{\ddagger}$
}

Institut National de la Santé et de la Recherche Médicale, CHU Lille, UMR-S 1172-JPArc, LabEx DISTALZ, Université de Lille, Lille, France

Alzheimer's disease (AD) is the most common neurodegenerative disorder in elderly people. AD is characterized by a progressive cognitive decline and it is neuropathologically defined by two hallmarks: extracellular deposits of aggregated $\beta$-amyloid $(A \beta)$ peptides and intraneuronal fibrillar aggregates of hyper- and abnormally phosphorylated Tau proteins. AD results from multiple genetic and environmental risk factors. Epidemiological studies reported beneficial effects of caffeine, a non-selective adenosine receptors antagonist. In the present review, we discuss the impact of caffeine and of adenosinergic system modulation on AD, in terms of pathology and therapeutics.

Keywords: Alzheimer's disease, memory, caffeine, adenosine, adenosine receptors

\section{INTRODUCTION}

Alzheimer's disease (AD) is the most common form of dementia, representing $70 \%$ of cases affecting more than 40 millions patients worldwide (Scheltens et al., 2016). The anatomopathological diagnosis of $\mathrm{AD}$ is based on the presence of two lesions: amyloid deposits and neurofibrillary tangles. Amyloid deposits are composed of extracellular accumulation of beta amyloid peptides $(A B)$ resulting from the sequential cleavage of the amyloid precursor protein (APP) by beta- and gamma-secretases (De Strooper, 2010). Neurofibrillary tangles result from intra-neuronal accumulation of hyper- and abnormally phosphorylated Tau protein (defined as "Tau pathology"). Although the development and progression of both lesions are involved in the evolution of clinical deficits, the spreading of Tau pathology has been suggested as a more reliable predictor for cognitive impairment (Brier et al., 2016). In parallel, complex neuroinflammatory and neuroimmune processes, involving innate (notably microglia, astrocytes) and adaptive ( $T$ cells, Tregs cells) brain resident or peripheral immune cells, were shown to be strongly involved in both the development of AD lesions and cognitive deficits (for reviews see Dansokho et al., 2017; Leyns and Holtzman, 2017; Ising and Heneka, 2018; Laurent et al., 2018). The role of immune system into the AD pathophysiological process is supported by the findings of several variants in immunityrelated genes resulted as susceptibility markers in genome wide association studies (i.e., CR1, SPI1, the MS4As, TREM2, ABCA7, CD33, and INPP5D; Efthymiou and Goate, 2017).

Alzheimer's disease is mostly a sporadic disease (Scheltens et al., 2016); indeed, the etiological mechanisms underlying neuropathological changes in $\mathrm{AD}$ remain unclear so far, but they appear to be dependent on both genetic and environmental factors (Reitz et al., 2011). A recent study estimated that around $35 \%$ of dementia is attributable to a combination of modifiable lifestyle factors, some of them linked to cardio-metabolic changes (Livingston et al., 2017). Interestingly, compelling epidemiologic evidences support that habitual consumption of caffeine is prone to 
reduce cognitive decline with aging and to reduce $\mathrm{AD}$ risk (reviewed in Flaten et al., 2014; Cunha, 2016). This minireview will be focused on the current knowledge regarding the mechanisms underlying caffeine beneficial effects in $\mathrm{AD}$, and specifically on how such positive effects are ascribable to an impact of caffeine on adenosinergic signaling (Figure 1).

\section{CAFFEINE, COGNITION, AND AD}

The pharmacological actions of caffeine are complex and greatly differ depending on its dosage and concentration. Its effect may also depend on its metabolites: paraxanthine (1,7-dimethylxanthine), theophylline (3,7-dimethylxanthine), and theobromine (1,3-dimethylxanthine). Pharmacokinetics and metabolism of caffeine have been extensively reviewed recently (Nehlig, 2018).

In healthy subjects, besides its positive effect on mood, alertness, attention and information processing (Sawyer et al., 1982; Fredholm et al., 1999, 2005; Smit and Rogers, 2000; Lorist and Tops, 2003; Fisone et al., 2004; Haskell et al., 2005), caffeine has also been shown to favor neuronal excitability in neocortex (Kerkhofs et al., 2017) and memory consolidation (Borota et al., 2014). Its widespread consumption and beneficial impact on cognitive functions maintenance emphasizes the need to study the effects of caffeine consumption on $\mathrm{AD}$ pathophysiology and aging-associated decline. In 2002, a retrospective study supported an inverse correlation between caffeine intake and age at $\mathrm{AD}$ onset. Indeed, $\mathrm{AD}$ patients presented an average daily caffeine intake of about $74 \pm 98 \mathrm{mg}$ during the 20 years preceding $\mathrm{AD}$ diagnosis, whereas age-matched controls had a larger average daily caffeine intake of $199 \pm 136 \mathrm{mg}$ during the corresponding 20 years of their lifetime (Maia and de Mendonça, 2002). Five years later, a 4 -year-long observational study, in a group of over 7,000 participants, revealed a significantly lower deterioration in verbal retrieval and visuospatial memory in $>65$ years old women, who consumed over 3 cups of coffee a day as compared to women who consumed 1 cup of coffee a day or less. However, such findings were not reported in men (Ritchie et al., 2007). A longitudinal population-based study found that a daily intake of 3-5 cups of coffee in middle-aged people lower the risk of $\mathrm{AD}$ and dementia disease by around $65 \%$ as compared to lower amounts of coffee (Eskelinen et al., 2009). A meta-analysis of 9 cohorts and 2 case-control studies also reported an inverse correlation between $\mathrm{AD}$ incidence and caffeine intake (Santos et al., 2010). In contrast, the HonoluluAsian Aging Study reported no significant correlation between midlife coffee or caffeine consumption and the risk of dementia or cognitive impairment. However, the authors reported that the higher caffeine intake ( $>277.5 \mathrm{mg}$ per day) was associated with a decreased risk to present, at autopsy, any of the neuropathological lesions, i.e., AD-related lesions, microvascular ischemic lesions, cortical Lewy bodies, hippocampal sclerosis, or generalized atrophy (Gelber et al., 2011). A further possible positive impact of caffeine on cerebrospinal fluid (CSF) production and turnover, finally facilitating $A \beta$ clearance, was even suggested (Wostyn et al., 2011).
In line with the latter epidemiological and neuropathological observations, compelling experimental evidence, both in vivo and in vitro, give reliable proof-of-concept that caffeine has a strong potential toward AD pathology and associated cognitive deficits. In seminal studies, Arendash et al. demonstrated that caffeine intake in transgenic mice overexpressing mutated APP (APPsw) alleviates cognitive decline induced by $A \beta$ and lowers the concentration of this neurotoxic peptide in both preventive and therapeutic paradigms. APPsw mice chronically treated from 4 to 9.5 months of age with caffeinated water (300 $\mathrm{mg} / \mathrm{l}$, corresponding to $500 \mathrm{mg}$ per day in humans), exhibited improved working and spatial memories as well as reduced levels of hippocampal $A \beta_{1-40}$ and $A \beta_{1-42}$. At late pathological stages (18-19 month), APPsw mice treated similarly for $4-5$ weeks display reversed memory deficits and reduced $A \beta$ deposits and soluble $A \beta$ levels in entorhinal cortex as well as in hippocampus (Arendash et al., 2006, 2009). Furthermore, in SweAPP N2a cell cultures - murine neuron-like cells transfected with the human "Swedish" mutant APP - the treatment with different concentrations of caffeine (below $10 \mu \mathrm{M}$ ) induced a reduced production of $A \beta_{1-40}$ and $A \beta_{1-42}$ (Arendash et al., 2006). Molecular dynamics simulations recently suggested that the hydrophobic core-recognition motif of amyloid peptide formation could be physically blocked by caffeine, thereby abolishing the self-assembly formation (Sharma and Paul, 2016). Our previous studies also emphasize that chronic caffeine treatment prevents the development of spatial memory deficits, reduces hippocampal Tau phosphorylation and proteolytic fragments as well as mitigates parenchymal neuroinflammation in a model of AD-like Tau pathology (Laurent et al., 2014). All these data are in accordance with the decrease of $\mathrm{A} \beta$ production and Tau phosphorylation in rabbits fed with a high cholesterol diet - an experimental model for sporadic AD - treated with low and high doses of caffeine (0.5-30 mg per day, corresponding to a maximal $60 \mathrm{mg}$ per day in humans) (Prasanthi et al., 2010). Thus, a growing body of evidence indicates that caffeine is able to reduce behavioral and pathological features associated with $\mathrm{AD}$ in models of sporadic and early onset (genetically-linked) AD. It is however important to mention that a recent study performed in transgenic mice developing both amyloid and Tau lesions suggests that chronic caffeine consumption may lead to adverse effect notably by enhancing BPSD (Behavioral and Psychological Symptoms of Dementia)-like symptoms that may interfere with the ability of caffeine to normalize memory deficits (Baeta-Corral et al., 2018), underlying possible side effects that need to be carefully evaluated in future trials in patients. Overall, while a large amount of epidemiological and experimental evidence implies that caffeine and associated methylxanthines may have beneficial long-term protective effects against latelife cognitive impairment or decline, clinical evaluations are still warranted. Relationships between caffeine levels and $\mathrm{AD}$ biomarkers remain also unclear so far (Travassos et al., 2015). Therefore, a long-term interventional randomized controlled study taking into account CSF and blood biomarkers but also possible side effects is required to definitively conclude on the therapeutic potential of caffeine in $\mathrm{AD}$ and dementia. Possibly, future studies will also need to evaluate whether caffeine 


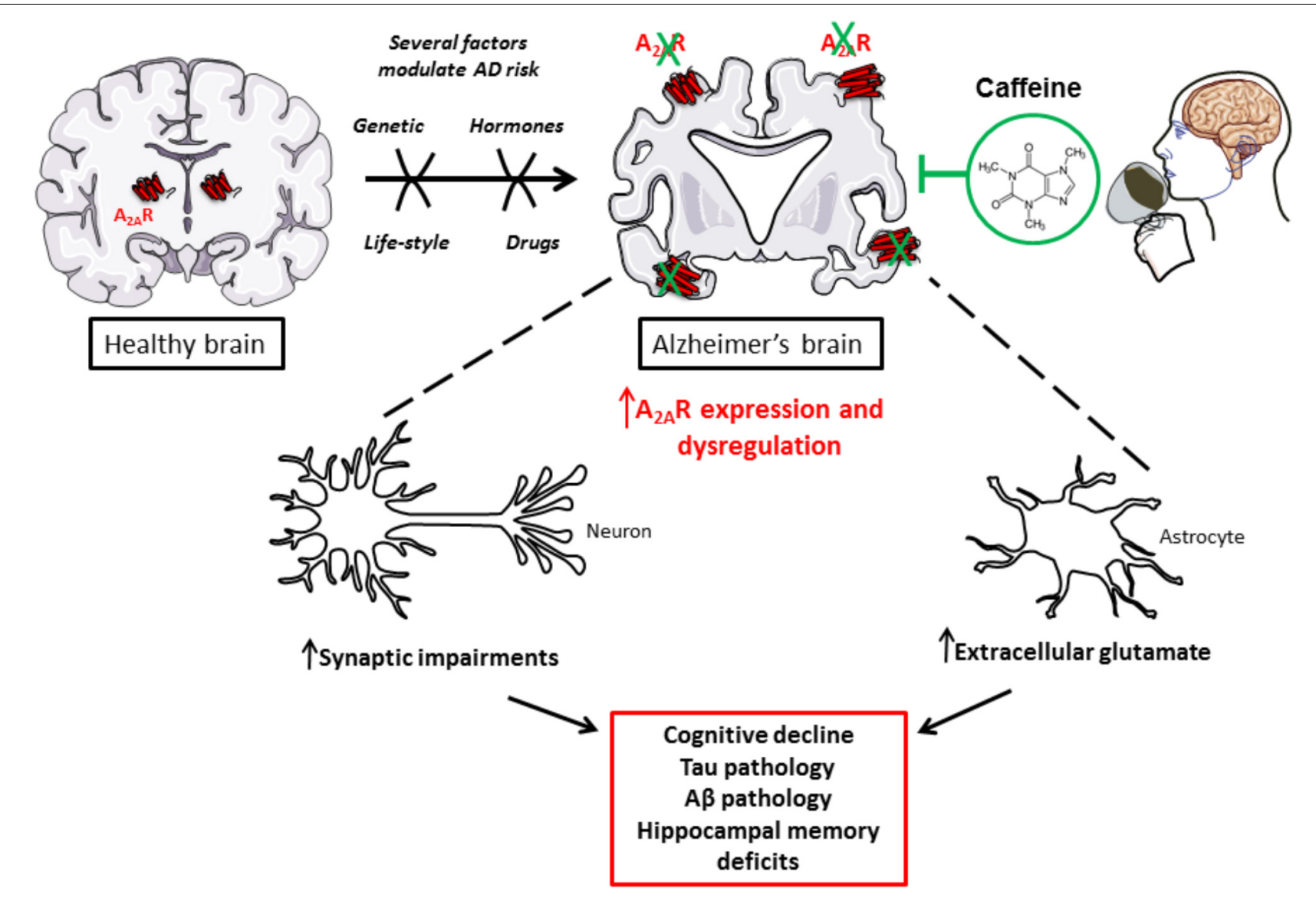

FIGURE 1 | Caffeine, as a new promising treatment to counterbalance toxic impact of $A_{2 A} R$ dysregulation in $A D$.

itself or its metabolites are presumably responsible for clinical and metabolic changes. Indeed, previous data indicate that the CSF and plasma level of one of the main metabolites of caffeine, theobromine, could be associated with $A \beta_{42}$ CSF levels suggesting that it may have a particular impact (Travassos et al., 2015).

\section{CAFFEINE, ADENOSINE, AND ADENOSINE RECEPTORS}

Under normal consumption conditions, caffeine acts as a non-selective competitive antagonist of the four subtypes of G-protein-coupled adenosine $P 1$ receptors: $A_{1}, A_{2 A}, A_{2 B}$, and $A_{3}$ whose endogenous ligand is adenosine, a purinergic nucleoside. Among them, $A_{1}$ and $A_{2 A}$ receptor subtypes are the most abundant in the mammalian brain. $\mathrm{A}_{1}$ Rs are widely distributed throughout the central nervous system (CNS) while $\mathrm{A}_{2 \mathrm{~A}} \mathrm{Rs}$ are mainly expressed by striato-pallidal medium spiny neurons in the striatum. However, $\mathrm{A}_{2 \mathrm{~A}} \mathrm{R}$ is largely expressed within other area of the CNS at lower levels. $A_{1} R$ and $A_{2 A} R$ are both G-proteincoupled receptor, the former being coupled to inhibitory $G$ proteins $(\mathrm{Gi})$, the latter to activatory $G$ proteins $\left(G_{\text {olf }}\right.$ or $G$; Fredholm et al., 2005). Adenosine receptors are expressed by neurons, glial and endothelial cells. $A_{1}$ Rs particularly regulate excitatory transmission at both pre- and post-synaptic sites. In synapses, $\mathrm{A}_{2 \mathrm{~A}} \mathrm{Rs}$ are known to fine-tune synaptic plasticity, notably by regulating presynaptic release of glutamate (Cunha, 2016). Recent data emphasized an important role of $A_{2 A} R s$ in regulating glutamate and GABA uptake by astrocytes (Matos et al., 2012a,b; Cristóvão-Ferreira et al., 2013).

Adenosine can be generated from adenine nucleosides present inside the cells or on the outer side of the plasma membrane (Zimmermann, 2000), via intracellular or extracellular $5^{\prime}$ nucleotidases enzymes (Figure 2). At extracellular level, several mechanisms can contribute to adenosine generation. ATP can be released by distinct mechanisms: (1) by exocytosis from both glial cells (Imura et al., 2013) or neurons, where it is released as co-transmitter and as a neurotransmitter acting on P2 purinergic receptors (Zimmermann, 1994; Burnstock, 2007); (2) by lysosomal exocytosis (Jung et al., 2013, 2014) or (3) via hemichannels (Chever et al., 2014; Lopatár et al., 2015; Orellana et al., 2015; Orellana, 2016). Cyclic adenosine $3^{\prime}-5^{\prime}$ monophosphate (cAMP) can also be released by cells via a probenecid-sensitive transporter or converted into $5^{\prime}$ AMP inside the cells and then released (Rosenberg and $\mathrm{Li}$, 1995; Brundege et al., 1997). Once out of the cell, these nucleotides undergo an enzymatic conversion through coupled 


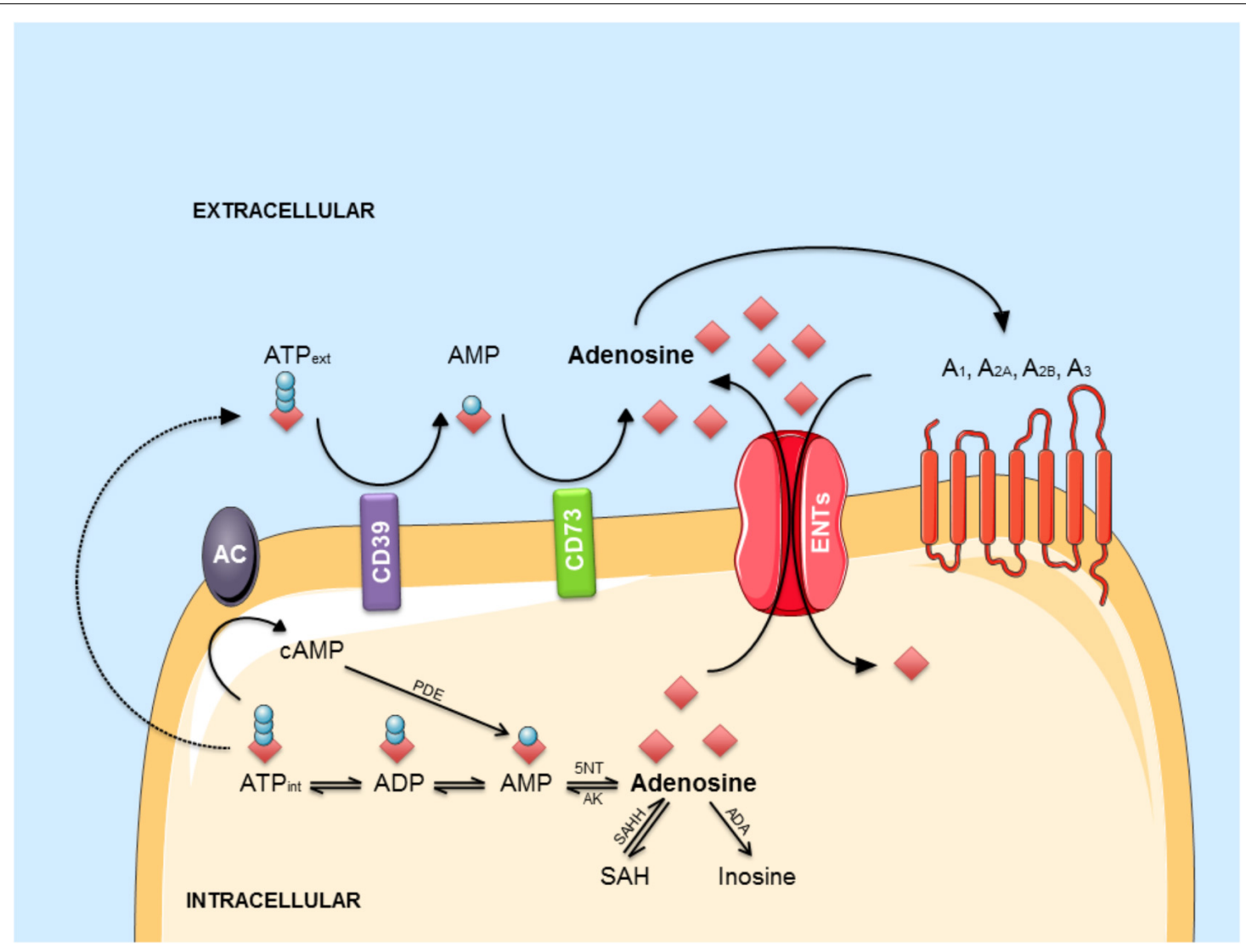

FIGURE 2 | The adenosinergic pathway. Intracellular adenosine is generated from AMP or SAH. After intracellular uptake, it is phosphorylated to AMP by AK or converted into inosine by ADA. ATP is released into the extracellular environment and hydrolyzed by the concerted action of CD39 and CD73 into adenosine. In response to metabolic stress, adenosine accumulates in the extracellular environment. Extracellular adenosine can bind to four different G-protein-coupled receptors $\left(A_{1}, A_{2 A}, A_{2 B}\right.$, and $\left.A_{3}\right)$ or be transported back into the cell via ENTs. Abbreviations: $A_{1}, A_{2 A}, A_{2 B}, A_{3}$, adenosine receptors; AC, adenylyl cyclase; $A D A$, adenosine deaminase; AK, adenosine kinase; AMP, adenosine monophosphate; ATP, adenosine triphosphate; CAMP, cyclic AMP; ENT, equilibrative nucleoside transporter; 5NT, 5'-nucleotidase; PDE, phosphodiesterase; SAH, S-adenosyl-homocysteine; SAHH, S-adenosyl-homocysteine hydrolase.

ectonucleotidases CD39/CD73 which sequentially converts ATP/ADP to AMP and AMP to adenosine (Zimmermann, 2006; Zimmermann et al., 2012). Adenosine may be then further transformed to inosine by extracellular adenosine deaminase enzymes (ADA) or may enter inside the cell through bidirectional equilibrative nucleoside transporters, ENT1 and ENT2, where it may undergo intracellular ADA action thus generating inosine, or it may be phosphorylated to AMP by adenosine kinases (ADK; see Borea et al., 2016). In the cytosol, AMP-specific $5^{\prime}$-nucleotidase, mainly accounts for adenosine generation during enhanced metabolic load (Hunsucker et al., 2001) while $S$-adenosylhomocysteine (SAH) pathway plays a negligible role (see Latini and Pedata, 2001) except regarding the non-receptor mediated epigenetics effect of adenosine (Williams-Karnesky et al., 2013). Once generated, intracellularly-generated adenosine can be released via ENT1 and ENT2 in the outer space of the cell (King et al., 2006) contributing to the maintenance of a basal adenosine tone (Lee et al., 2018).

Extracellular adenosine is central in the regulation of several brain functions as it is tightly linked to the energetic state of neurons; its local increase notably reflects the depletion of
ATP intracellular storage (Parkinson et al., 2011) that may be rather due to increased metabolic demand than metabolite availability. This happens in several conditions, including hypoxia, hypoglycemia and high frequency stimulation/seizures. It has also been found that adenosine extracellular concentration varies during physiological processes, where it represents a brain fatigue factor (Porkka-Heiskanen et al., 1997), thus, playing a role in sleep-wake cycle (reviewed in Murillo-Rodriguez et al., 2003; Porkka-Heiskanen and Kalinchuk, 2011; Chen, 2014; Huang et al., 2014), and cerebral blood flow (Gordon et al., 2008; McClure et al., 2011).

In neuronal cells, adenosine regulates survival and neurotransmitter release (Cunha et al., 2008). In glial cells, it is involved in the control of differentiation (Coppi et al., 2013, 2015), reactivity (Newell et al., 2015; Madeira et al., 2016; Liu et al., 2018), proliferation (George et al., 2015), and neurotransmitter uptake (Matos et al., 2012a,b, 2013; Cristóvão-Ferreira et al., 2013). The role of the physiological increased adenosine tone has been interpreted as involved in neuronal homeostasis, representing a sort of link between energy metabolism and neuronal excitability. Instead, under 
condition of cellular stress, adenosine tone is raised up that could eventually counteract glutamate neurotransmission (Brambilla et al., 2005). This phenomenon occurs in pathological contexts such as epilepsy (Ilie et al., 2012; Boison, 2016; Cieslak et al., 2018), ischemia or oxygen-glucose deprivation (Melani et al., 1999; zur Nedden et al., 2014), inflammation (Mukandala et al., 2016), and AD (Alonso-Andrés et al., 2018).

To which extent changes of adenosine level, recently observed in the temporal cortex of $\mathrm{AD}$ patients (AlonsoAndrés et al., 2018), are involved in the pathophysiological development remains an unsolved question. On the one hand, an increase in the endogenous level of adenosine in the diseased parenchyma could represent a beneficial response, at least at short-term. Indeed, first, increased adenosine tone allows a higher production of SAH, which suppresses methyltransferase activity and subsequently reduces DNA methylation (WilliamsKarnesky et al., 2013). DNA methylation is an interesting aspect of the adenosine effect to be taken into account, since dynamic and complex changes in DNA methylation profiles have been reported in the brain of both mice and patients with AD (Sanchez-Mut et al., 2013; Qazi et al., 2018). Secondly, increased adenosine would be prone to favor $A_{1} R$ activation, presumably normalizing the hyperexcitability and excitotoxicity network occurring in AD parenchyma (Blum et al., 2003; Cunha, 2016). Therefore, increasing adenosine tone, for instance by blocking ENT1 transporter, could be seen as a therapeutic option in AD as nicely recently demonstrated (Lee et al., 2018). Given that chronic $A_{1} R$ activation favors activation effect and excitotoxicity occurrence due to receptor internalization (Blum et al., 2003) and that $A_{2 A} R$ overactivation leads to memory impairments and $\mathrm{AD}$ pathology development (see below), the benefits afforded by a chronic increase of adenosine tone (Lee et al., 2018) are presumably not mediated by receptor-mediated effects. On the other hand, brain adenosine surge in $\mathrm{AD}$ could represent a detrimental signal fitting with the above-mentioned ability of caffeine to prevent $\mathrm{AD}$ pathology and related cognitive deficits. Several publications emphasize that blockade of $\mathrm{A}_{2 \mathrm{~A}}$ (see below) but also $A_{1}$ (Dennissen et al., 2016) and $A_{3}$ (Li et al., 2015) receptors might be of interest in the treatment of $\mathrm{AD}$.

\section{THE ROLE OF ADENOSINERGIC $A_{2 A}$ RECEPTOR IN AD}

Persisting higher adenosine tone is thought to preferentially lead to $A_{2 A} R$ activation over $A_{1} R$ (Cunha, 2016). Several works argue for a detrimental impact of $\mathrm{A}_{2 \mathrm{~A}} \mathrm{R}$ in $\mathrm{AD}$ pathophysiology, which could readily explain the beneficial effects of caffeine. In line with a central role of $\mathrm{A}_{2 \mathrm{~A}} \mathrm{Rs}$ in $\mathrm{AD}$, recently, an association between a polymorphism of the ADORA2A gene with hippocampal volume in mild cognitive impairment and $\mathrm{AD}$ was reported (Horgusluoglu-Moloch et al., 2017). $\mathrm{A}_{2 \mathrm{~A}} \mathrm{R}$ expression and function have been shown abnormally enhanced in $\mathrm{AD}$ brain and, accordingly, blocking $\mathrm{A}_{2 \mathrm{~A}} \mathrm{R}$ has been proven beneficial; thus, underlying the detrimental contributing impact of the enhancement of $\mathrm{A}_{2 \mathrm{~A}} \mathrm{R}$ signaling in the pathological brain. Indeed, besides a higher adenosine tone, $\mathrm{A}_{2 \mathrm{~A}} \mathrm{R}$ expression and function appear to be dysregulated in AD. Early studies on cortical plasma membranes revealed that cortex of $\mathrm{AD}$ patients exhibit enhanced $\mathrm{A}_{2 \mathrm{~A}} \mathrm{R}$ binding and response (Albasanz et al., 2008). More recent data emphasized that $\mathrm{A}_{2 \mathrm{~A}} \mathrm{R}$ expression is abnormally increased not only in brain cortical parenchyma of AD patients (Orr et al., 2015; Temido-Ferreira et al., 2018) but also on transgenic mouse models (Viana da Silva et al., 2016; Faivre et al., 2018; Lee et al., 2018; Orr et al., 2018; Silva et al., 2018). $\mathrm{A}_{2 \mathrm{~A}} \mathrm{R}$ changes have been shown to occur at both neuronal/synaptic (Viana da Silva et al., 2016; Temido-Ferreira et al., 2018; Silva et al., 2018) and astroglial (Orr et al., 2015, 2018; Lee et al., 2018; Faivre et al., 2018) levels. Interestingly, the sole activation of $\mathrm{A}_{2 \mathrm{~A}} \mathrm{R}$ induced by a brain injection of an agonist is sufficient to promote memory deficits (Pereira et al., 2005; Pagnussat et al., 2015). In addition, conditional neuronal activation of $A_{2 A} R$ or related transduction pathways using optogenetics ( $\mathrm{Li}$ et al., 2015) promotes memory and plasticity deficits in hippocampus (Giménez-Llort et al., 2007; Batalha et al., 2013, 2016; TemidoFerreira et al., 2018). With regards to astrocytes, activating $\mathrm{A}_{2 \mathrm{~A}} \mathrm{R}$ (Matos et al., 2013) or associated transduction pathways in astrocytes is also prone to favor the emergence of hippocampal deficits with impaired glutamate uptake, thanks to a regulation of the $\mathrm{Na}^{+} / \mathrm{K}^{+}$ATPase regulating GLT-1 transporter, presumably favoring memory deficits (Matos et al., 2012a,b, 2013; Orr et al., 2015). On the other side, $A_{2 A} R$ blockade or deletion was also found to counteract synaptotoxicity and memory deficits acutely induced by $\beta$-amyloid peptides (Dall'Igna et al., 2003, 2007; Canas et al., 2009). Furthermore, several works underline that blocking $\mathrm{A}_{2 \mathrm{~A}} \mathrm{R}$ using pharmacological or genetic tools improves memory deficits and even pathology as well as parenchymal inflammation in different experimental transgenic $\mathrm{AD}$ models chronically developing either amyloid burden and Tau pathology (Orr et al., 2015, 2018; Laurent et al., 2016; Faivre et al., 2018; Silva et al., 2018). Even this still remains controversial (Lu et al., 2016), it is noteworthy that some data had indicated that $\mathrm{A}_{2 \mathrm{~A}} \mathrm{R}$ might impact on the production of $\mathrm{A} \beta$ in vitro (Nagpure and Bian, 2014). Finally, this is in line with our observations that CD73 blockade, likely reducing adenosine tone and $\mathrm{A}_{2 \mathrm{~A}} \mathrm{R}$ activity, favors the non-amyloidogenic pathway, counteracting $\mathrm{A} \beta$ formation. The overall view on $\mathrm{A}_{2 \mathrm{~A}} \mathrm{R}$ as a therapeutic target thus looks promising.

It is notable that $\mathrm{A}_{2 \mathrm{~A}} \mathrm{R}$ antagonism has been reported as a promising approach in Parkinson's Disease prone to counteract both motor, cognitive symptoms and $\alpha$-synproteinopathy (Kachroo and Schwarzschild, 2012; Ferreira et al., 2016, 2018). While some clinical trials failed to demonstrate a large benefit of $\mathrm{A}_{2 \mathrm{~A}} \mathrm{R}$ blockade as monotherapy in $\mathrm{PD}$ patients even reducing off-time (SYN-115; Hauser et al., 2014), the $\mathrm{A}_{2 \mathrm{~A}} \mathrm{R}$ antagonist istradefylline (KW-6002) is still tested in phase III and it is already approved as therapeutic option for PD patients in Japan where it is early administered in association with L-DOPA to reduce motor symptoms and dyskinesia (Borea et al., 2016; Oertel and Schulz, 2016). Considering safety and tolerability of $\mathrm{A}_{2 \mathrm{~A}} \mathrm{R}$ antagonists in $\mathrm{PD}$ trials, it is tempting to consider that a repurposing of these molecules could be of great interest in $\mathrm{AD}$ considering their ability to normalize cognitive and to reduce 
several pathophysiological mechanisms, from synaptic deficits to lesion development passing through neuroinflammation.

\section{CONCLUSION}

$\mathrm{AD}$ is an important medico-societal concern. Our current knowledge in the field supports that the dysregulation of the adenosinergic signaling is certainly important for the pathophysiological development of $\mathrm{AD}$ and constitutes a major therapeutic target that needs to be thoughtfully evaluated. Considering their known safety, evaluating caffeine and $\mathrm{A}_{2 \mathrm{~A}} \mathrm{R}$ antagonists in clinical trials can be considered as a priority in the field. Whether modulating adenosine tone itself is a valuable strategy worth also to be investigated considering recent encouraging results (Lee et al., 2018), underlying mechanisms still need to be further elucidated. Owing to the important contribution of adenosine pathways to blood-brain-barrier permeability (Kim and Bynoe, 2015), physiological plasticity, neurotrophin actions (Rebola et al., 2008; Jerónimo-Santos et al., 2014) or even to the peripheral adaptive immune system lastly recognized as playing an important role in $\mathrm{AD}$ (Linden and Cekic, 2012; Antonioli et al., 2013; Laurent et al., 2018), careful investigations on processes underlying beneficial effects and potential side effects are warranted.

\section{REFERENCES}

Albasanz, J. L., Perez, S., Barrachina, M., Ferrer, I., and Martín, M. (2008). Upregulation of adenosine receptors in the frontal cortex in Alzheimer's disease. Brain Pathol. 18, 211-219. doi: 10.1111/j.1750-3639.2007.00112.x

Alonso-Andrés, P., Albasanz, J. L., Ferrer, I., and Martín, M. (2018). Purine-related metabolites and their converting enzymes are altered in frontal, parietal and temporal cortex at early stages of Alzheimer's disease pathology. Brain Pathol. doi: 10.1111/bpa.12592 [Epub ahead of print].

Antonioli, L., Blandizzi, C., Pacher, P., and Haskó, G. (2013). Immunity, inflammation and cancer: a leading role for adenosine. Nat. Rev. Cancer 13, 842-857. doi: 10.1038/nrc3613

Arendash, G. W., Mori, T., Cao, C., Mamcarz, M., Runfeldt, M., Dickson, A., et al. (2009). Caffeine reverses cognitive impairment and decreases brain amyloidbeta levels in aged Alzheimer's disease mice. J. Alzheimers Dis. 17, 661-680. doi: 10.3233/JAD-2009-1087

Arendash, G. W., Schleif, W., Rezai-Zadeh, K., Jackson, E. K., Zacharia, L. C., Cracchiolo, J. R., et al. (2006). Caffeine protects Alzheimer's mice against cognitive impairment and reduces brain beta-amyloid production. Neuroscience 142, 941-952. doi: 10.1016/j.neuroscience.2006.07.021

Baeta-Corral, R., Johansson, B., and Giménez-Llort, L. (2018). Long-term treatment with low-dose caffeine worsens BPSD-like profile in 3xTg-AD mice model of Alzheimer's disease and affects mice with normal aging. Front. Pharmacol. 9:79. doi: 10.3389/fphar.2018.00079

Batalha, V. L., Ferreira, D. G., Coelho, J. E., Valadas, J. S., Gomes, R., TemidoFerreira, M., et al. (2016). The caffeine-binding adenosine A2A receptor induces age-like HPA-axis dysfunction by targeting glucocorticoid receptor function. Sci. Rep. 6:31493. doi: 10.1038/srep31493

Batalha, V. L., Pego, J. M., Fontinha, B. M., Costenla, A. R., Valadas, J. S., Baqi, Y., et al. (2013). Adenosine A(2A) receptor blockade reverts hippocampal stress-induced deficits and restores corticosterone circadian oscillation. Mol. Psychiatry 18, 320-331. doi: 10.1038/mp.2012.8

Blum, D., Hourez, R., Galas, M.-C., Popoli, P., and Schiffmann, S. N. (2003). Adenosine receptors and Huntington's disease: implications for pathogenesis and therapeutics. Lancet Neurol. 2, 366-374.

\section{AUTHOR CONTRIBUTIONS}

LC, KC, DB, CM, and VG-M wrote the manuscript. LC, KC, EF, $\mathrm{AD}, \mathrm{DV}, \mathrm{LB}, \mathrm{DB}, \mathrm{CM}$, and VG-M reviewed the manuscript.

\section{FUNDING}

Our laboratory was supported by grants from France Alzheimer, Fondation de France, FHU VasCog research network, programmes d'Investissements d'Avenir LabEx (excellence laboratory) DISTALZ (Development of Innovative Strategies for a Transdisciplinary approach to ALZheimer's disease), ANR (ADORATAU and ADORASTrAU to DB, SPREADTAU and GRAND to LB), Fondation pour la Recherche Médicale, LECMA/Alzheimer Forschung Initiative, Fondation Plan Alzheimer as well as Inserm, CNRS, Université Lille 2, Lille Métropole Communauté Urbaine, Région Nord/Pas-de-Calais, FEDER, DN2M, and FUI MEDIALZ. LC was supported by the Italian Society of Pharmacology (SIF) and LabEx DISTALZ. EF was supported by ANR ADORATAU and University of Lille. AD was supported by France Alzheimer. CM was supported by Région Hauts de France (COGNADORA). VG-M was supported by Fondation pour la Recherche Médicale (SPF20160936000).

Boison, D. (2016). Adenosinergic signaling in epilepsy. Neuropharmacology 104, 131-139. doi: 10.1016/j.neuropharm.2015.08.046

Borea, P. A., Gessi, S., Merighi, S., and Varani, K. (2016). Adenosine as a multisignalling guardian angel in human diseases: When, where and how does it exert its protective effects? Trends Pharmacol. Sci. 37, 419-434. doi: 10.1016/ j.tips.2016.02.006

Borota, D., Murray, E., Keceli, G., Chang, A., Watabe, J. M., Ly, M., et al. (2014). Post-study caffeine administration enhances memory consolidation in humans. Nat. Neurosci. 17, 201-203. doi: 10.1038/nn.3623

Brambilla, D., Chapman, D., and Greene, R. (2005). Adenosine mediation of presynaptic feedback inhibition of glutamate release. Neuron 46, 275-283. doi: 10.1016/j.neuron.2005.03.016

Brier, M. R., Gordon, B., Friedrichsen, K., McCarthy, J., Stern, A., Christensen, J., et al. (2016). Tau and A $\beta$ imaging, CSF measures, and cognition in Alzheimer's disease. Sci. Transl. Med. 8:338ra66. doi: 10.1126/scitranslmed.aaf2362

Brundege, J. M., Diao, L., Proctor, W. R., and Dunwiddie, T. V. (1997). The role of cyclic AMP as a precursor of extracellular adenosine in the rat hippocampus. Neuropharmacology 36, 1201-1210.

Burnstock, G. (2007). Purine and pyrimidine receptors. Cell. Mol. Life Sci. 64, 1471-1483. doi: 10.1007/s00018-007-6497-0

Canas, P. M., Porciúncula, L. O., Cunha, G. M. A., Silva, C. G., Machado, N. J., Oliveira, J. M. A., et al. (2009). Adenosine A2A receptor blockade prevents synaptotoxicity and memory dysfunction caused by beta-amyloid peptides via p38 mitogen-activated protein kinase pathway. J. Neurosci. 29, 14741-14751. doi: 10.1523/JNEUROSCI.3728-09.2009

Chen, J.-F. (2014). Adenosine receptor control of cognition in normal and disease. Int. Rev. Neurobiol. 119, 257-307. doi: 10.1016/B978-0-12-801022-8. 00012-X

Chever, O., Lee, C.-Y., and Rouach, N. (2014). Astroglial connexin43 hemichannels tune basal excitatory synaptic transmission. J. Neurosci. 34, 11228-11232. doi: 10.1523/JNEUROSCI.0015-14.2014

Cieslak, A., Smith, E. E., Lysack, J., and Ismail, Z. (2018). Case series of mild behavioral impairment: toward an understanding of the early stages of neurodegenerative diseases affecting behavior and cognition. Int. Psychogeriatr. 30, 273-280. doi: 10.1017/S1041610217001855 
Coppi, E., Cellai, L., Maraula, G., Dettori, I., Melani, A., Pugliese, A. M., et al. (2015). Role of adenosine in oligodendrocyte precursor maturation. Front. Cell. Neurosci. 9:155. doi: 10.3389/fncel.2015.00155

Coppi, E., Cellai, L., Maraula, G., Pugliese, A. M., and Pedata, F. (2013). Adenosine $\mathrm{A}_{2} \mathrm{~A}$ receptors inhibit delayed rectifier potassium currents and cell differentiation in primary purified oligodendrocyte cultures. Neuropharmacology 73, 301-310. doi: 10.1016/j.neuropharm.2013.05.035

Cristóvão-Ferreira, S., Navarro, G., Brugarolas, M., Pérez-Capote, K., Vaz, S. H., Fattorini, G., et al. (2013). A1R-A2AR heteromers coupled to Gs and G i/0 proteins modulate GABA transport into astrocytes. Purinergic Signal. 9, 433-449. doi: 10.1007/s11302-013-9364-5

Cunha, G. M. A., Canas, P. M., Melo, C. S., Hockemeyer, J., Müller, C. E., Oliveira, C. R., et al. (2008). Adenosine A2A receptor blockade prevents memory dysfunction caused by $\beta$-amyloid peptides but not by scopolamine or MK- 801 . Exp. Neurol. 210, 776-781. doi: 10.1016/j.expneurol.2007.11.013

Cunha, R. A. (2016). How does adenosine control neuronal dysfunction and neurodegeneration? J. Neurochem. 139, 1019-1055. doi: 10.1111/jnc.13724

Dall'Igna, O. P., Fett, P., Gomes, M. W., Souza, D. O., Cunha, R. A., and Lara, D. R. (2007). Caffeine and adenosine A(2a) receptor antagonists prevent betaamyloid (25-35)-induced cognitive deficits in mice. Exp. Neurol. 203, 241-245. doi: 10.1016/j.expneurol.2006.08.008

Dall'Igna, O. P., Porciúncula, L. O., Souza, D. O., Cunha, R. A., Lara, D. R., and Dall'lgna, O. P. (2003). Neuroprotection by caffeine and adenosine A2A receptor blockade of beta-amyloid neurotoxicity. Br. J. Pharmacol. 138, 1207-1209. doi: 10.1038/sj.bjp.0705185

Dansokho, C., Aucouturier, P., and Dorothée, G. (2017). Beneficial effect of interleukin-2-based immunomodulation in Alzheimer-like pathology. Brain 140:e39. doi: 10.1093/brain/awx108

De Strooper, B. (2010). Proteases and proteolysis in Alzheimer disease: a multifactorial view on the disease process. Physiol. Rev. 90, 465-494. doi: 10.1152/physrev.00023.2009

Dennissen, F. J. A., Anglada-Huguet, M., Sydow, A., Mandelkow, E., and Mandelkow, E.-M. (2016). Adenosine A1 receptor antagonist rolofylline alleviates axonopathy caused by human Tau $\Delta$ K280. Proc. Natl. Acad. Sci. U.S.A. 113, 11597-11602. doi: 10.1073/pnas.1603119113

Efthymiou, A. G., and Goate, A. M. (2017). Late onset Alzheimer's disease genetics implicates microglial pathways in disease risk. Mol. Neurodegener. 12:43. doi: 10.1186/s13024-017-0184-x

Eskelinen, M. H., Ngandu, T., Tuomilehto, J., Soininen, H., and Kivipelto, M. (2009). Midlife coffee and tea drinking and the risk of late-life dementia: a population-based CAIDE study. J. Alzheimers Dis. 16, 85-91. doi: 10.3233/JAD2009-0920

Faivre, E., Coehlo, J. E., Zornbach, K., Malik, E., Baqi, Y., Schneider, M., et al. (2018). Beneficial effect of a selective adenosine $A_{2 A}$ receptor antagonist in the APPswe/PS1de9 mouse model of Alzheimer's Disease. Front. Mol. Neurosci. 10:14. doi: 10.3389/fnmol.2018.00235

Ferreira, J. J., Lees, A., Rocha, J.-F., Poewe, W., Rascol, O., Soares-da-Silva, P., et al. (2016). Opicapone as an adjunct to levodopa in patients with Parkinson's disease and end-of-dose motor fluctuations: a randomised, double-blind, controlled trial. Lancet Neurol. 15, 154-165. doi: 10.1016/S1474-4422(15) 00336- 1

Ferreira, R. N., de Miranda, A. S., Rocha, N. P., Silva, A. C. S. E., Teixeira, A. L., and da Silva Camargos, E. R. (2018). Neurotrophic factors in Parkinson's disease: What have we learned from pre-clinical and clinical studies? Curr. Med. Chem. doi: 10.2174/0929867325666180313101536 [Epub ahead of print].

Fisone, G., Borgkvist, A., and Usiello, A. (2004). Caffeine as a psychomotor stimulant: mechanism of action. Cell. Mol. Life Sci. 61, 857-872. doi: 10.1007/ s00018-003-3269-3

Flaten, V., Laurent, C., Coelho, J. E., Sandau, U., Batalha, V. L., Burnouf, S., et al. (2014). From epidemiology to pathophysiology: what about caffeine in Alzheimer's disease? Biochem. Soc. Trans. 42, 587-592. doi: 10.1042/ BST20130229

Fredholm, B. B., Bättig, K., Holmén, J., Nehlig, A., and Zvartau, E. E. (1999). Actions of caffeine in the brain with special reference to factors that contribute to its widespread use. Pharmacol. Rev. 51, 83-133.

Fredholm, B. B., Chen, J.-F., Cunha, R. A., Svenningsson, P., and Vaugeois, J.M. (2005). Adenosine and brain function. Int. Rev. Neurobiol. 63, 191-270. doi: 10.1016/S0074-7742(05)63007-3
Gelber, R. P., Petrovitch, H., Masaki, K. H., Ross, G. W., and White, L. R. (2011). Coffee intake in midlife and risk of dementia and its neuropathologic correlates. J. Alzheimers Dis. 23, 607-615. doi: 10.3233/JAD-2010-101428

George, J., Gonçalves, F. Q., Cristóvão, G., Rodrigues, L., Meyer Fernandes, J. R., Gonçalves, T., et al. (2015). Different danger signals differently impact on microglial proliferation through alterations of ATP release and extracellular metabolism. Glia 63, 1636-1645. doi: 10.1002/glia.22833

Giménez-Llort, L., Schiffmann, S. N., Shmidt, T., Canela, L., Camón, L., Wassholm, M., et al. (2007). Working memory deficits in transgenic rats overexpressing human adenosine A2A receptors in the brain. Neurobiol. Learn. Mem. 87, 42-56. doi: 10.1016/j.nlm.2006.05.004

Gordon, G. R. J., Choi, H. B., Rungta, R. L., Ellis-Davies, G. C. R., and MacVicar, B. A. (2008). Brain metabolism dictates the polarity of astrocyte control over arterioles. Nature 456, 745-749. doi: 10.1038/nature07525

Haskell, C. F., Kennedy, D. O., Wesnes, K. A., and Scholey, A. B. (2005). Cognitive and mood improvements of caffeine in habitual consumers and habitual nonconsumers of caffeine. Psychopharmacology 179, 813-825. doi: 10.1007/s00213004-2104-3

Hauser, R. A., Olanow, C. W., Kieburtz, K. D., Pourcher, E., Docu-Axelerad, A., Lew, M., et al. (2014). Tozadenant (SYN115) in patients with Parkinson's disease who have motor fluctuations on levodopa: a phase $2 \mathrm{~b}$, double-blind, randomised trial. Lancet Neurol. 13, 767-776. doi: 10.1016/S1474-4422(14) 70148-6

Horgusluoglu-Moloch, E., Nho, K., Risacher, S. L., Kim, S., Foroud, T., Shaw, L. M., et al. (2017). Targeted neurogenesis pathway-based gene analysis identifies ADORA2A associated with hippocampal volume in mild cognitive impairment and Alzheimer's disease. Neurobiol. Aging 60, 92-103. doi: 10.1016/ j.neurobiolaging.2017.08.010

Huang, Z.-L., Zhang, Z., and Qu, W.-M. (2014). Roles of adenosine and its receptors in sleep-wake regulation. Int. Rev. Neurobiol. 119, 349-371. doi: 10.1016/B978-0-12-801022-8.00014-3

Hunsucker, S. A., Spychala, J., and Mitchell, B. S. (2001). Human cytosolic 5'nucleotidase I: characterization and role in nucleoside analog resistance. J. Biol. Chem. 276, 10498-10504. doi: 10.1074/jbc.M011218200

Ilie, A., Raimondo, J. V., and Akerman, C. J. (2012). Adenosine release during seizures attenuates GABAA receptor-mediated depolarization. J. Neurosci. 32, 5321-5332. doi: 10.1523/JNEUROSCI.5412-11.2012

Imura, Y., Morizawa, Y., Komatsu, R., Shibata, K., Shinozaki, Y., Kasai, H., et al. (2013). Microglia release ATP by exocytosis. Glia 61, 1320-1330. doi: 10.1002/ glia. 22517

Ising, C., and Heneka, M. T. (2018). Functional and structural damage of neurons by innate immune mechanisms during neurodegeneration. Cell Death Dis. 9:120. doi: 10.1038/s41419-017-0153-x

Jerónimo-Santos, A., Batalha, V. L., Müller, C. E., Baqi, Y., Sebastião, A. M., Lopes, L. V., et al. (2014). Impact of in vivo chronic blockade of adenosine A2A receptors on the BDNF-mediated facilitation of LTP. Neuropharmacology 83, 99-106. doi: 10.1016/j.neuropharm.2014.04.006

Jung, J., Jo, H. W., Kwon, H., and Jeong, N. Y. (2014). ATP release through lysosomal exocytosis from peripheral nerves: the effect of lysosomal exocytosis on peripheral nerve degeneration and regeneration after nerve injury. Biomed Res. Int. 2014:936891. doi: 10.1155/2014/936891

Jung, J., Shin, Y. H., Konishi, H., Lee, S. J., and Kiyama, H. (2013). Possible ATP release through lysosomal exocytosis from primary sensory neurons. Biochem. Biophys. Res. Commun. 430, 488-493. doi: 10.1016/j.bbrc.2012. 12.009

Kachroo, A., and Schwarzschild, M. A. (2012). Adenosine A2A receptor gene disruption protects in an $\alpha$-synuclein model of Parkinson's disease. Ann. Neurol. 71, 278-282. doi: 10.1002/ana.22630

Kerkhofs, A., Xavier, A. C., da Silva, B. S., Canas, P. M., Idema, S., Baayen, J. C., et al. (2017). Caffeine controls glutamatergic synaptic transmission and pyramidal neuron excitability in human neocortex. Front. Pharmacol. 8:899. doi: 10.3389/fphar.2017.00899

Kim, D.-G., and Bynoe, M. S. (2015). A2A adenosine receptor regulates the human blood-brain barrier permeability. Mol. Neurobiol. 52, 664-678. doi: 10.1007/ s12035-014-8879-2

King, A. E., Ackley, M. A., Cass, C. E., Young, J. D., and Baldwin, S. A. (2006). Nucleoside transporters: from scavengers to novel therapeutic targets. Trends Pharmacol. Sci. 27, 416-425. doi: 10.1016/j.tips.2006.06.004 
Latini, S., and Pedata, F. (2001). Adenosine in the central nervous system: release mechanisms and extracellular concentrations. J. Neurochem. 79, 463-484.

Laurent, C., Buée, L., and Blum, D. (2018). Tau and neuroinflammation: What impact for Alzheimer's disease and tauopathies? Biomed. J. 41, 21-33. doi: 10.1016/J.BJ.2018.01.003

Laurent, C., Burnouf, S., Ferry, B., Batalha, V. L., Coelho, J. E., Baqi, Y., et al. (2016). A2A adenosine receptor deletion is protective in a mouse model of Tauopathy. Mol. Psychiatry 21, 97-107. doi: 10.1038/mp. 2015.115

Laurent, C., Eddarkaoui, S., Derisbourg, M., Leboucher, A., Demeyer, D., Carrier, S., et al. (2014). Beneficial effects of caffeine in a transgenic model of Alzheimer's disease-like tau pathology. Neurobiol. Aging 35, 2079-2090. doi: 10.1016/j.neurobiolaging.2014.03.027

Lee, C.-C., Chang, C.-P., Lin, C.-J., Lai, H.-L., Kao, Y.-H., Cheng, S.-J., et al. (2018). Adenosine augmentation evoked by an ENT1 inhibitor improves memory impairment and neuronal plasticity in the APP/PS1 mouse model of Alzheimer's disease. Mol. Neurobiol. doi: 10.1007/s12035-018-1030-z [Epub ahead of print].

Leyns, C. E. G., and Holtzman, D. M. (2017). Glial contributions to neurodegeneration in tauopathies. Mol. Neurodegener. 12:50. doi: 10.1186/ s13024-017-0192-x

Li, S., Geiger, N. H., Soliman, M. L., Hui, L., Geiger, J. D., and Chen, X. (2015). Caffeine, through adenosine A3 receptor-mediated actions, suppresses amyloid- $\beta$ protein precursor internalization and amyloid- $\beta$ generation. J. Alzheimers Dis. 47, 73-83. doi: 10.3233/JAD-142223

Linden, J., and Cekic, C. (2012). Regulation of lymphocyte function by adenosine. Arterioscler. Thromb. Vasc. Biol. 32, 2097-2103. doi: 10.1161/ATVBAHA.111. 226837

Liu, Y., Alahiri, M., Ulloa, B., Xie, B., and Sadiq, S. A. (2018). Adenosine A2A receptor agonist ameliorates EAE and correlates with Th1 cytokine-induced blood brain barrier dysfunction via suppression of MLCK signaling pathway. Immun. Inflamm. Dis. 6, 72-80. doi: 10.1002/iid3.187

Livingston, G., Sommerlad, A., Orgeta, V., Costafreda, S. G., Huntley, J., Ames, D., et al. (2017). Dementia prevention, intervention, and care. Lancet 390, 2673-2734. doi: 10.1016/S0140-6736(17)31363-6

Lopatár, J., Dale, N., and Frenguelli, B. G. (2015). Pannexin-1-mediated ATP release from area CA3 drives mGlu5-dependent neuronal oscillations. Neuropharmacology 93, 219-228. doi: 10.1016/j.neuropharm.2015.01.014

Lorist, M. M., and Tops, M. (2003). Caffeine, fatigue, and cognition. Brain Cogn. $53,82-94$.

Lu, J., Cui, J., Li, X., Wang, X., Zhou, Y., Yang, W., et al. (2016). An antiParkinson's disease drug via targeting adenosine A2A receptor enhances amyloid- $\beta$ generation and $\gamma$-secretase activity. PLoS One 11:e0166415. doi: 10.1371 /journal.pone.0166415

Madeira, M. H., Boia, R., Elvas, F., Martins, T., Cunha, R. A., Ambrósio, A. F., et al. (2016). Selective A2A receptor antagonist prevents microglia-mediated neuroinflammation and protects retinal ganglion cells from high intraocular pressure-induced transient ischemic injury. Transl. Res. 169, 112-128. doi: 10.1016/j.trsl.2015.11.005

Maia, L., and de Mendonça, A. (2002). Does caffeine intake protect from Alzheimer's disease? Eur. J. Neurol. 9, 377-382.

Matos, M., Augusto, E., Agostinho, P., Cunha, R. A., and Chen, J.-F. (2013). Antagonistic interaction between adenosine $\mathrm{A} 2 \mathrm{~A}$ receptors and $\mathrm{Na}^{+} / \mathrm{K}^{+}$ATPase- $\alpha 2$ controlling glutamate uptake in astrocytes. J. Neurosci. 33, 1849218502. doi: 10.1523/JNEUROSCI.1828-13.2013

Matos, M., Augusto, E., Machado, N. J., dos Santos-Rodrigues, A., Cunha, R. A., and Agostinho, P. (2012a). Astrocytic adenosine A2A receptors control the amyloid- $\beta$ peptide-induced decrease of glutamate uptake. J. Alzheimers Dis. 31, 555-567. doi: 10.3233/JAD-2012-120469

Matos, M., Augusto, E., Santos-Rodrigues, A. D., Schwarzschild, M. A., Chen, J.F., Cunha, R. A., et al. (2012b). Adenosine A2A receptors modulate glutamate uptake in cultured astrocytes and gliosomes. Glia 60, 702-716. doi: 10.1002/glia. 22290

McClure, J. M., O'Leary, D. S., and Scislo, T. J. (2011). Neural and humoral control of regional vascular beds via A1 adenosine receptors located in the nucleus tractus solitarii. Am. J. Physiol. Regul. Integr. Comp. Physiol. 300, R744-R755. doi: 10.1152/ajpregu.00565.2010
Melani, A., Pantoni, L., Corsi, C., Bianchi, L., Monopoli, A., Bertorelli, R., et al. (1999). Striatal outflow of adenosine, excitatory amino acids, gammaaminobutyric acid, and taurine in awake freely moving rats after middle cerebral artery occlusion: correlations with neurological deficit and histopathological damage. Stroke 30, 2448-2454.

Mukandala, G., Tynan, R., Lanigan, S., and O'Connor, J. J. (2016). The Effects of Hypoxia and Inflammation on Synaptic Signaling in the CNS. Brain Sci. 6:E6. doi: 10.3390/brainsci6010006

Murillo-Rodriguez, E., Blanco-Centurion, C., Sanchez, C., Piomelli, D., and Shiromani, P. J. (2003). Anandamide enhances extracellular levels of adenosine and induces sleep: an in vivo microdialysis study. Sleep 26, 943-947.

Nagpure, B. V., and Bian, J.-S. (2014). Hydrogen sulfide inhibits A2A adenosine receptor agonist induced $\beta$-amyloid production in SH-SY5Y neuroblastoma cells via a cAMP dependent pathway. PLoS One 9:e88508. doi: 10.1371/journal. pone. 0088508

Nehlig, A. (2018). Interindividual differences in caffeine metabolism and factors driving caffeine consumption. Pharmacol. Rev. 70, 384-411. doi: 10.1124/pr. 117.014407

Newell, E. A., Exo, J. L., Verrier, J. D., Jackson, T. C., Gillespie, D. G., JaneskoFeldman, K., et al. (2015). 2',3'-cAMP, 3'-AMP, 2'-AMP and adenosine inhibit TNF- $\alpha$ and CXCL10 production from activated primary murine microglia via A2A receptors. Brain Res. 1594, 27-35. doi: 10.1016/j.brainres.2014.10.059

Oertel, W., and Schulz, J. B. (2016). Current and experimental treatments of Parkinson disease: a guide for neuroscientists. J. Neurochem. 139(Suppl. 1), 325-337. doi: 10.1111/jnc. 13750

Orellana, J. A. (2016). Physiological functions of glial cell hemichannels. Adv. Exp. Med. Biol. 949, 93-108. doi: 10.1007/978-3-319-40764-7_5

Orellana, J. A., Moraga-Amaro, R., Díaz-Galarce, R., Rojas, S., Maturana, C. J., Stehberg, J., et al. (2015). Restraint stress increases hemichannel activity in hippocampal glial cells and neurons. Front. Cell. Neurosci. 9:102. doi: 10.3389/ fncel.2015.00102

Orr, A. G., Hsiao, E. C., Wang, M. M., Ho, K., Kim, D. H., Wang, X., et al. (2015). Astrocytic adenosine receptor A2A and Gs-coupled signaling regulate memory. Nat. Neurosci. 18, 423-434. doi: 10.1038/nn.3930

Orr, A. G., Lo, I., Schumacher, H., Ho, K., Gill, M., Guo, W., et al. (2018). Istradefylline reduces memory deficits in aging mice with amyloid pathology. Neurobiol. Dis. 110, 29-36. doi: 10.1016/j.nbd.2017.10.014

Pagnussat, N., Almeida, A. S., Marques, D. M., Nunes, F., Chenet, G. C., Botton, P. H. S., et al. (2015). Adenosine A(2A) receptors are necessary and sufficient to trigger memory impairment in adult mice. Br. J. Pharmacol. 172, 3831-3845. doi: $10.1111 /$ bph. 13180

Parkinson, F. E., Damaraju, V. L., Graham, K., Yao, S. Y. M., Baldwin, S. A., Cass, C. E., et al. (2011). Molecular biology of nucleoside transporters and their distributions and functions in the brain. Curr. Top. Med. Chem. 11, 948-972.

Pereira, G. S., Rossato, J. I., Sarkis, J. J. F., Cammarota, M., Bonan, C. D., and Izquierdo, I. (2005). Activation of adenosine receptors in the posterior cingulate cortex impairs memory retrieval in the rat. Neurobiol. Learn. Mem. 83, 217-223. doi: 10.1016/j.nlm.2004.12.002

Porkka-Heiskanen, T., and Kalinchuk, A. V. (2011). Adenosine, energy metabolism and sleep homeostasis. Sleep Med. Rev. 15, 123-135. doi: 10.1016/j.smrv.2010. 06.005

Porkka-Heiskanen, T., Strecker, R. E., Thakkar, M., Bjorkum, A. A., Greene, R. W., and McCarley, R. W. (1997). Adenosine: a mediator of the sleep-inducing effects of prolonged wakefulness. Science 276, 1265-1268.

Prasanthi, J. R. P., Dasari, B., Marwarha, G., Larson, T., Chen, X., Geiger, J. D., et al. (2010). Caffeine protects against oxidative stress and Alzheimer's diseaselike pathology in rabbit hippocampus induced by cholesterol-enriched diet. Free Radic. Biol. Med. 49, 1212-1220. doi: 10.1016/j.freeradbiomed.2010.07.007

Qazi, T. J., Quan, Z., Mir, A., and Qing, H. (2018). Epigenetics in Alzheimer's disease: perspective of DNA methylation. Mol. Neurobiol. 55, 1026-1044. doi: 10.1007/s12035-016-0357-6

Rebola, N., Lujan, R., Cunha, R. A., and Mulle, C. (2008). Adenosine A2A receptors are essential for long-term potentiation of NMDA-EPSCs at hippocampal mossy fiber synapses. Neuron 57, 121-134. doi: 10.1016/j.neuron.2007.11.023

Reitz, C., Brayne, C., and Mayeux, R. (2011). Epidemiology of Alzheimer disease. Nat. Rev. Neurol. 7, 137-152. doi: 10.1038/nrneurol.2011.2

Ritchie, K., Carrière, I., de Mendonca, A., Portet, F., Dartigues, J. F., Rouaud, O., et al. (2007). The neuroprotective effects of caffeine: a prospective population 
study (the Three City Study). Neurology 69, 536-545. doi: 10.1212/01.wnl. $0000266670.35219 .0 \mathrm{c}$

Rosenberg, P. A., and Li, Y. (1995). Adenylyl cyclase activation underlies intracellular cyclic AMP accumulation, cyclic AMP transport, and extracellular adenosine accumulation evoked by beta-adrenergic receptor stimulation in mixed cultures of neurons and astrocytes derived from rat cerebral cortex. Brain Res. 692, 227-232.

Sanchez-Mut, J. V., Aso, E., Panayotis, N., Lott, I., Dierssen, M., Rabano, A., et al. (2013). DNA methylation map of mouse and human brain identifies target genes in Alzheimer's disease. Brain 136, 3018-3027. doi: 10.1093/brain/ awt 237

Santos, C., Costa, J., Santos, J., Vaz-Carneiro, A., and Lunet, N. (2010). Caffeine intake and dementia: systematic review and meta-analysis. J. Alzheimers Dis. 20(Suppl. 1), S187-S204. doi: 10.3233/JAD-2010-091387

Sawyer, D. A., Julia, H. L., and Turin, A. C. (1982). Caffeine and human behavior: arousal, anxiety, and performance effects. J. Behav. Med. 5, 415-439.

Scheltens, P., Blennow, K., Breteler, M. M. B., de Strooper, B., Frisoni, G. B., Salloway, S., et al. (2016). Alzheimer's disease. Lancet 388, 505-517. doi: 10.1016/S0140-6736(15)01124-1

Sharma, B., and Paul, S. (2016). Action of caffeine as an amyloid inhibitor in the aggregation of A $\beta 16-22$ peptides. J. Phys. Chem. B 120, 9019-9033. doi: 10.1021/acs.jpcb.6b03892

Silva, A. C., Lemos, C., Goncalves, F. Q., Pliassova, A. V., Machado, N. J., Silva, H. B., et al. (2018). Blockade of adenosine A2A receptors recovers early deficits of memory and plasticity in the triple transgenic mouse model of Alzheimer's disease. Neurobiol. Dis. 350, 99-108. doi: 10.1016/j.nbd.2018. 05.024

Smit, H. J., and Rogers, P. J. (2000). Effects of low doses of caffeine on cognitive performance, mood and thirst in low and higher caffeine consumers. Psychopharmacology 152, 167-173.

Temido-Ferreira, M., Ferreira, D. G., Batalha, V. L., Marques-Morgado, I., Coelho, J. E., Pereira, P., et al. (2018). Age-related shift in LTD is dependent on neuronal adenosine A2A receptors interplay with mGluR5 and NMDA receptors. Mol. Psychiatry doi: 10.1038/s41380-018-0110-9 [Epub ahead of print].

Travassos, M., Santana, I., Baldeiras, I., Tsolaki, M., Gkatzima, O., Sermin, G., et al. (2015). Does caffeine consumption modify cerebrospinal fluid amyloid$\beta$ levels in patients with Alzheimer's disease? J. Alzheimers Dis. 47, 1069-1078. doi: $10.3233 /$ JAD- 150374
Viana da Silva, S., Haberl, M. G., Zhang, P., Bethge, P., Lemos, C., Gonçalves, N., et al. (2016). Early synaptic deficits in the APP/PS1 mouse model of Alzheimer's disease involve neuronal adenosine A2A receptors. Nat. Commun. 7:11915. doi: $10.1038 /$ ncomms 11915

Williams-Karnesky, R. L., Sandau, U. S., Lusardi, T. A., Lytle, N. K., Farrell, J. M., Pritchard, E. M., et al. (2013). Epigenetic changes induced by adenosine augmentation therapy prevent epileptogenesis. J. Clin. Invest. 123, 3552-3563. doi: 10.1172/JCI65636

Wostyn, P., Van Dam, D., Audenaert, K., and De Deyn, P. P. (2011). Increased cerebrospinal fluid production as a possible mechanism underlying caffeine's protective effect against Alzheimer's disease. Int. J. Alzheimers Dis. 2011:617420. doi: $10.4061 / 2011 / 617420$

Zimmermann, H. (1994). Signalling via ATP in the nervous system. Trends Neurosci. 17, 420-426.

Zimmermann, H. (2000). Extracellular metabolism of ATP and other nucleotides. Naunyn Schmiedebergs Arch. Pharmacol. 362, 299-309.

Zimmermann, H. (2006). Nucleotide signaling in nervous system development. Pflugers Arch. 452, 573-588. doi: 10.1007/s00424-0060067-4

Zimmermann, H., Zebisch, M., and Sträter, N. (2012). Cellular function and molecular structure of ecto-nucleotidases. Purinergic Signal. 8, 437-502. doi: 10.1007/s11302-012-9309-4

zur Nedden, S., Doney, A. S., and Frenguelli, B. G. (2014). Modulation of intracellular ATP determines adenosine release and functional outcome in response to metabolic stress in rat hippocampal slices and cerebellar granule cells. J. Neurochem. 128, 111-124. doi: 10.1111/jnc. 12397

Conflict of Interest Statement: The authors declare that the research was conducted in the absence of any commercial or financial relationships that could be construed as a potential conflict of interest.

Copyright (C) 2018 Cellai, Carvalho, Faivre, Deleau, Vieau, Buée, Blum, Mériaux and Gomez-Murcia. This is an open-access article distributed under the terms of the Creative Commons Attribution License (CC BY). The use, distribution or reproduction in other forums is permitted, provided the original author(s) and the copyright owner(s) are credited and that the original publication in this journal is cited, in accordance with accepted academic practice. No use, distribution or reproduction is permitted which does not comply with these terms. 